\title{
Sagittal Growth of the Nasomaxillary Complex during the Second Trimester of Human Prenatal Development
}

\author{
ALPHONSE R. BURDI
}

Department of Anatomy, University of Michigan, Ann Arbor, Michigan

Numerous investigations have been reported on the embryonic development of the human cranium and on the sequential appearance, number, and location of primary ossification centers in component bones of the facial skeleton. ${ }^{1-6}$ In general, these studies were exclusively qualitative and non-metric in content. Relatively few attempts, however, have been made to measure the changes in size, form, and proportionality of the upper facial region during human development. ${ }^{7-11}$

The purpose of the present study is to describe the patterns of growth in the craniofacial region during the second trimester of prenatal development. For this purpose a series of linear and angular analyses of the cranial base, nasal septum, and palate have been used. In addition to describing patterns of prenatal nasomaxillary growth, the findings of this study were correlated, whenever possible, with reported studies of craniofacial growth during the neonatal and early childhood periods. Consequently, the analyses used herein were adapted from cephalometric growth analyses currently recognized in orthodontics (Krogman and Sassouni).12 Furthermore, this study was founded on the concept that growth of the human body and, more specifically, the craniofacial region is a dynamic biological continuum that begins in embryonic development and continues through senility.

\section{Materials and Methods}

A series of 24 human fetuses ranging in size from 70 through $227 \mathrm{~mm}$. crown-rump length (CRL) were analyzed. Chronologically, this sample represented the 12th through

This investigation was supported (in part) by Research Grants DE 01822-01 from the National Institutes of Dental Research and by HD 00178 from the National Institute of Child Health and Human Development, National Institutes of Health, Bethesda, Md.

Received for publication February 24, 1964. the 24th weeks or the $2 \mathrm{~d}$ trimester of prenatal development. Only specimens free from gross cephalic deformations and fixed in 10 per cent neutral formalin were used.

Each head was removed from the body and sectioned parasagittally, immediately lateral to the nasal septum, in order to demonstrate the mid-line anatomical relationships of the cranial base, nasal septum, and palate. The anatomy exposed by this procedure was strikingly similar to that observed in lateral roentgen cephalograms. The specimens were analyzed indirectly through photographic recordings. In each photograph a plastic metric rule was placed routinely on the specimen in the plane of the nasal septum. In order to facilitate tracings, measurements, and statistical analyses, photographic prints were enlarged six times the actual size of the specimen.

From each enlarged photograph, outlines of the following regions were traced on 0.002 inch frosted acetate film: (1) sella turcica, (2) the pre- and postsellar segments of the cranial base, (3) the hard and soft palates, (4) the nasal septum, and (5) crista galli.

\section{Definition of Cephalometric Land- MARKS}

The following landmarks were located on each tracing (Fig. 1):

Nasion $(\mathrm{N})$. - - the most anterior point in the junction of the frontal and nasal bones

Sella (S).--a point, located by inspection, in the center of the concave sella turcica

Basion ( $\mathrm{Ba}$ ). - a point marking the greatest convexity of the anterior border of foramen magnum

Crista galli (CG). - the highest point on the superior contour of crista galli

Septal point (SP). - the most anterior point of the nasal septum

Anterior nasal spine (ANS). - the tip of the anterior nasal spine 
Posterior nasal spine (PNS). - the tip of the posterior margin of the palatine bone in the median plane

Uvular point (UP).- - the highest point on the posterior contour of the soft palate located by inspection

\section{Measurements of the Cranial Base}

Line $N-S$.- length of the anterior segment of the cranial base from nasion to sella

Line $S-B a$.- length of the posterior cranial base from sella to basion

Line $N-B a$.-length of the basicranial axis from nasion to basion

Line $N-S-B a$. - total length of the cranial base Angle $\mathrm{N}-\mathrm{S}-\mathrm{Ba}$ - - angular relationship between the anterior cranial base and the posterior cranial base read at the intersect of lines $\mathrm{N}-\mathrm{S}$ and S-Ba

\section{Measurements of the Nasal Septum}

Anterior septal height.-height of the anterior portion of the nasal septum represented by a perpendicular to the palatal plane from anterior nasal spine, ANS, to line S-N

Middle septal height.- -height of the middle portion of the nasal septum represented by a perpendicular to the palatal plane through crista galli (CG) and read as the distance from the palatal plane to line $\mathrm{S}-\mathrm{N}$

Posterior septal height.- -height of the posterior portion of the nasal septum represented by a perpendicular from the posterior nasal spine to line $\mathrm{S}-\mathrm{N}$

Anterior septal length.-length of the anterior portion of the nasal septum represented by a line parallel to the palatal plane passing through septal point (SP) and read as the distance between the anterior septal height perpendicular and septal point

Middle septal length.- length of the middle portion of the nasal septum represented by a line parallel to the palatal plane passing through septal point and read as the distance between the anterior and middle septal height perpendiculars

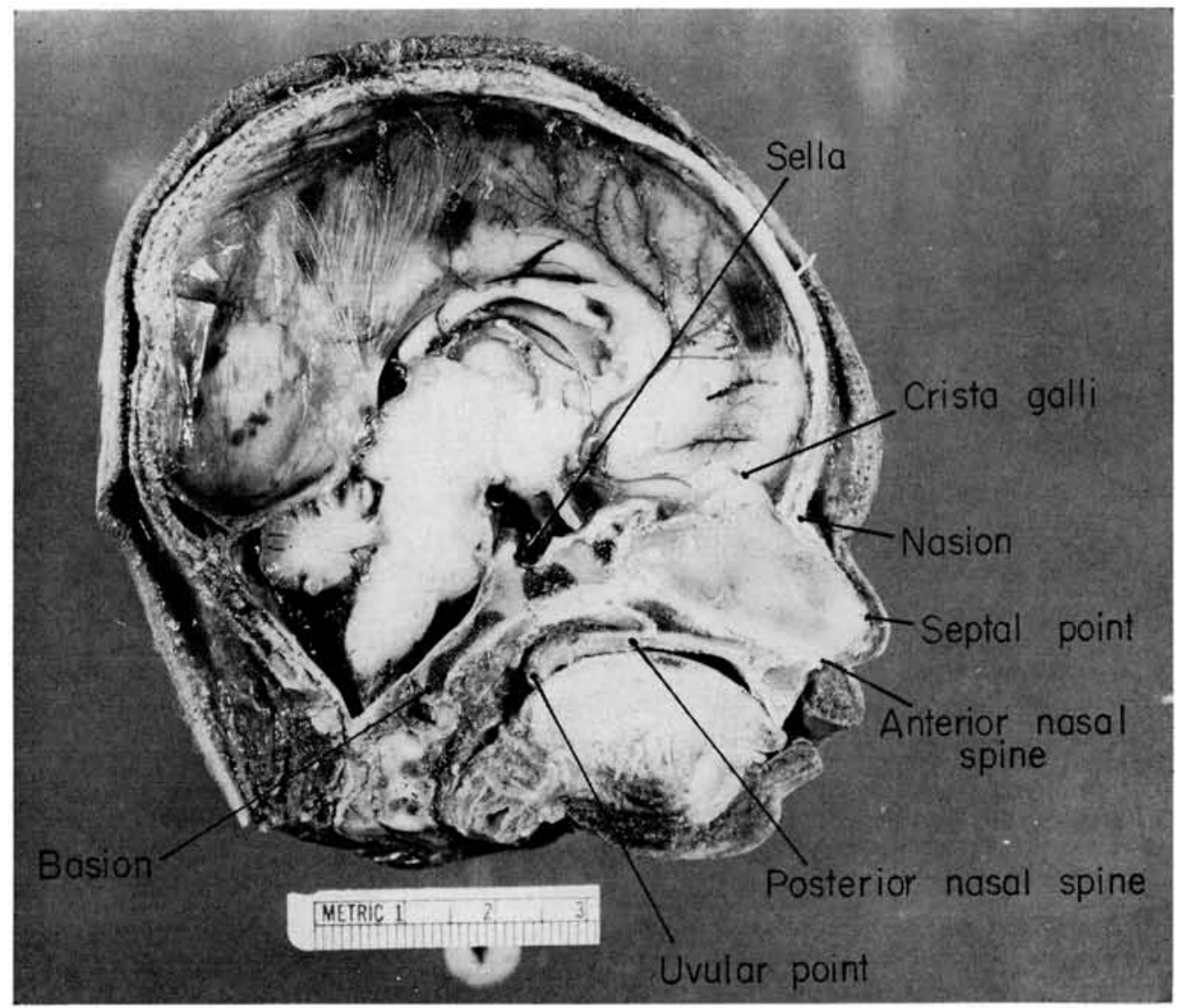

FIG. 1.-Typical fetal specimen indicating the cephalometric landmarks used 
TABLE 1

Growth in LeNGTH of THE FETAL CRANial BASE Region

A. Regression and correlation analyses

\begin{tabular}{|c|c|c|c|}
\hline Dimension* & $\begin{array}{l}\text { Regression Formula } \\
y=a+(b \times C \text { CRL })\end{array}$ & $\begin{array}{l}\text { Correlation } \\
\text { Coefficient }\end{array}$ & $\begin{array}{l}\text { Significance } \\
\text { at } 0.01 \text { Level }\end{array}$ \\
\hline $\begin{array}{l}\text { Ant. cranial base. } \\
\text { Post. cranial base. } \\
\text { Total base length. } \\
\text { Basicranial axis... }\end{array}$ & $\begin{array}{l}=14.38+(0.69 \times \mathrm{CRL}) \\
=27.85+(0.38 \times \mathrm{CRL}) \\
=42.31+(1.06 \times \mathrm{CRL}) \\
=36.42+(0.98 \times \mathrm{CRL})\end{array}$ & $\begin{array}{l}.972 \\
.882 \\
.962 \\
.952\end{array}$ & $\begin{array}{l}\text { Yes } \\
\text { Yes } \\
\text { Yes } \\
\text { Yes }\end{array}$ \\
\hline
\end{tabular}

B. Results of the $t$-test determinations of the significance of difference between absolute growth rates of several dimensions of the cranial base

\begin{tabular}{l|c|c|c|c}
\hline Comparison(s) between: & $\begin{array}{c}\text { Arithmetic } \\
\text { Difference } \\
\text { of } b \text {-Values }\end{array}$ & $t$ & $\begin{array}{c}\text { Significance } \\
\text { at } \\
0.01 \text { Level } \\
(t=2.693)\end{array}$ & $\begin{array}{c}\text { Degrees } \\
\text { of } \\
\text { Freedom }\end{array}$ \\
\hline Ant. and post. cranial base....... & 0.31 & 5.607 & Yes & 44 \\
Post. and total cranial base........ & .68 & 8.793 & Yes & 44 \\
Ant. and total cranial base....... & 0.37 & 5.056 & Yes & 44 \\
Total base length and basicranial axis & 0.08 & 0.862 & No & 44 \\
\hline
\end{tabular}

* Values for linear measurements are $\times 6$ the actual value. (This enlargement factor pertains to all linear measurements of the nasomaxillary area including the cranial base.)

Posterior septal length.-length of the posterior portion of the nasal septum represented by a line parallel to the palatal plane through septal point and read as the distance between the middle and posterior septal height perpendiculars

Angle $S-N-S P$.-angular slope of the anterosuperior border of the nasal septum measured at the intersect of lines $\mathrm{S}-\mathrm{N}$ and $\mathrm{N}-\mathrm{SP}$

Angle $S-N-A N S$. - angular relation of the upper face with the anterior cranial base read at the junction of lines S-N and N-ANS

\section{Measurements of the Palate}

Line ANS-PNS.-length of the hard palate from the anterior nasal spine to the posterior nasal spine

Lime $P N S-U P$.-length of the soft palate from the posterior nasal spine to the tip of the soft palate (UP)

Angle $A N S-P N S$ to $B a-N$.- angular relation of the palatal plane with the basicranial axis formed by the posterior projection of line ANS-PNS and read at the intersect of line $\mathrm{Ba}-\mathrm{N}$

Angle ANS-PNS to $S-B a$.- angular relation of the palatal plane with the posterior cranial base formed by the intersection of the posteriorly projected line ANS-PNS with line $\mathrm{S}-\mathrm{Ba}$

Angle ANS-PNS to $S-N$.- angular relation of the palatal plane with the anterior cranial base read at the intersection formed by the posterior projections of lines ANS-PNS and S-N

Linear measurements were recorded to the nearest millimeter, whereas all angular measurements were measured to the nearest half-degree. Graphs were drawn with the cephalometric measurements plotted along the ordinate and the crown-rump length along the abscissa. The resultant data were then subjected to group statistical analyses, which included tests for linear regression, coefficiency of correlation, significance of correlation, and the Student-Fisher $t$-test. The population size of this study did not warrant a more sophisticated statistical model. It is important to note that this empirical treatment of the data provided a more easily understood arrangement of the data and did not allude to the nature of the growth processes per se.

\section{Results}

CRanial Base.- In this study, the length of the entire cranial base (N-S-Ba), anterior cranial base $(\mathrm{N}-\mathrm{S})$, posterior cranial base ( $\mathrm{S}-\mathrm{Ba})$, and the length of the basicranial axis $(\mathrm{N}-\mathrm{Ba})$ were significantly correlated 
at the 0.01 level with increases in crownrump length from 70 to $227 \mathrm{~mm}$. (Table 1 , Fig. 2).

The length of the anterior cranial base demonstrated a regression coefficient, i.e., value $b$ of the linear regression formula $y=$ $a+(b x)$, of 0.69 units increase per unit increase in crown-rump length. More importantly, this regression coefficient was significantly greater than the 0.38 regression coefficient for the posterior cranial base.

The difference in the incremental growth of the two contiguous areas of the cranial base was further emphasized by the percentage increase of each base segment from the smallest $(70 \mathrm{~mm}$. CRL) to the largest fetus $(227 \mathrm{~mm}$. CRL). The anterior cranial base length exhibited an increase of 172 per cent when the smallest specimen was compared with the largest. However, the total cranial base and the posterior cranial base lengths demonstrated increases of 142 per cent and 109 per cent. When the percentage contribution of each segment to the entire cranial base length was considered, it was found that the anterior cranial base routinely contributed more than half of the total base length, i.e., 54 per cent at $70 \mathrm{~mm}$. CRL, 60 per cent at $227 \mathrm{~mm}$. CRL.

No significant correlation was found between increasing crown-rump length and the angular relationship between the anterior and posterior segments of the cranial base (Fig. 3). Table 2 shows that the cranial base angle, $\mathrm{N}-\mathrm{S}-\mathrm{Ba}$, was characterized by a regression line which was parallel to the abscissa as constructed by the formula $\mathrm{N}-\mathrm{S}$ $\mathrm{Ba}=126.40+0.02 \times \mathrm{CRL}$. The magnitude of the regression coefficient $(b=0.02)$ and a correlation coefficient of $r=0.247$ further emphasized the relative stability of the cranial base flexure.

NASAL SEPTUM.-The entire nasal septum as well as individual regions demonstrated a significant correlation between increasing septal height and crown-rump length (Table 3, Fig. 4). Distinct differences occurred in the rates at which the anterior, middle, and posterior regions of the septum increased in height. Analyses of group trends

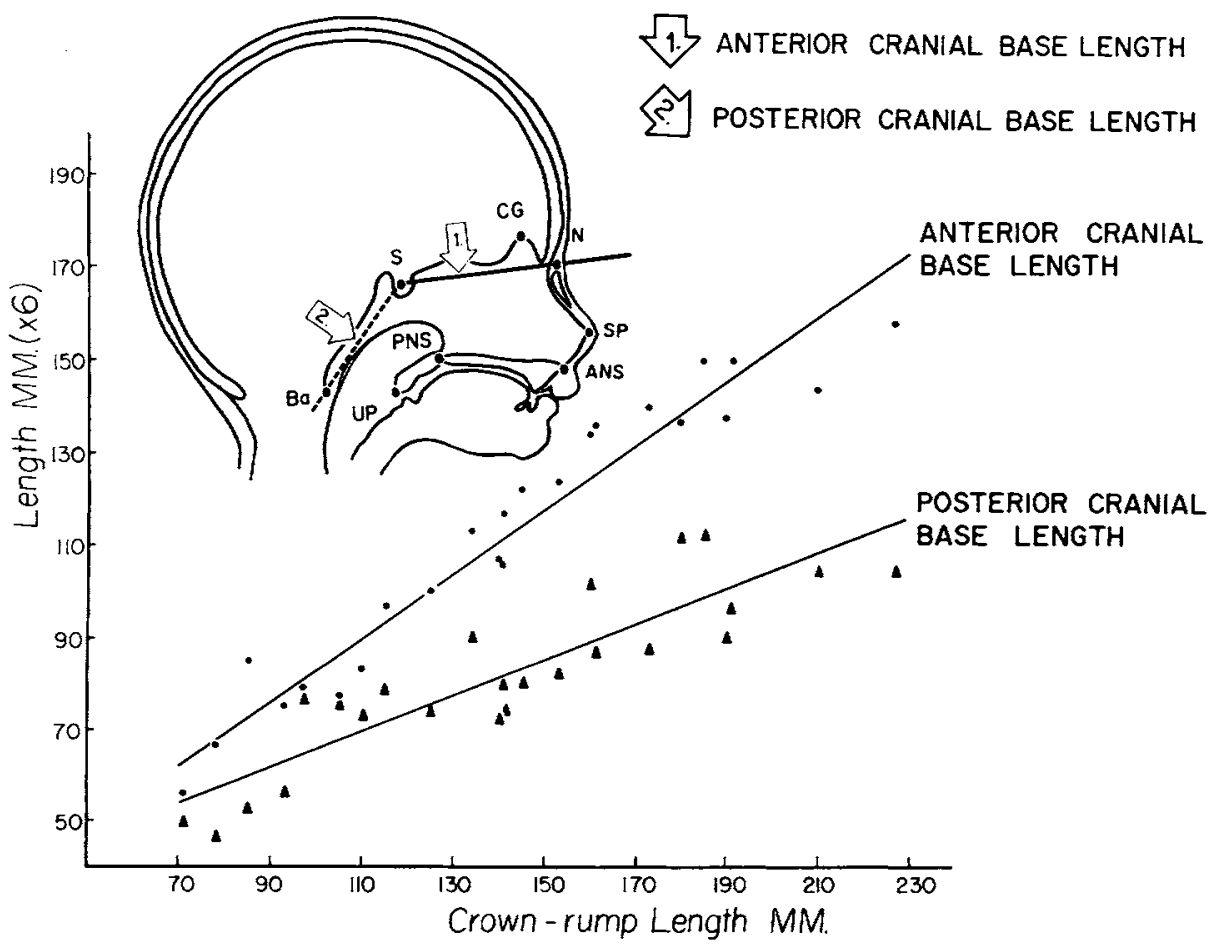

FIG. 2.-Sagittal growth of the cranial base 
TABLE 2

REGRESSION AND CORRELATION ANALYSES OF THE VARIOUS ANGULAR MEASUREMENTS OF THE FETAL CRANIOFACIAL REgION

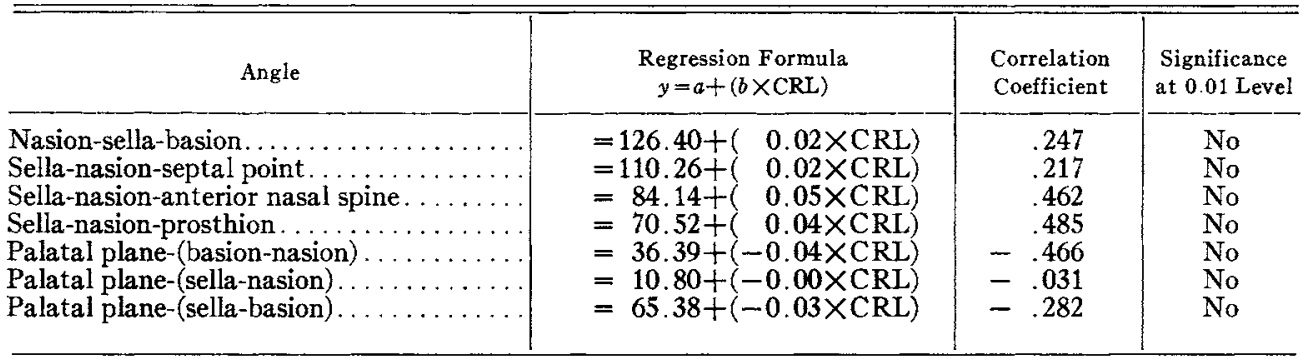

indicated that the unit increase in height per unit increase in crown-rump length was significantly greater at the 0.01 level for the anterior region of the septum $(b=0.33)$ than for the posterior septal height $(b=$ $0.24)$. No significant difference in regression coefficients existed for increases in height of the anterior and middle regions of the septum.

The relative lag in the growth of the posterior septal area was further discernible in a $t$-test comparison of the regression coefficients of the middle and posterior height perpendiculars. In Figure 4 the slope of the regression line for the middle septal height differed significantly from that of the posterior slope at the 0.05 level. On the basis of percentage increase in height from the 70 $\mathrm{mm}$. to the $227 \mathrm{~mm}$. crown-rump length fetus, the anterior region of the septum increased 157 per cent. This percentage increase was approximately the same for the middle region (156 per cent). The posterior segment, on the other hand, increased its height by only 148 per cent.

Changes in the length of the septum showed an entirely different pattern of septal growth (Table 4, Fig. 5). Although

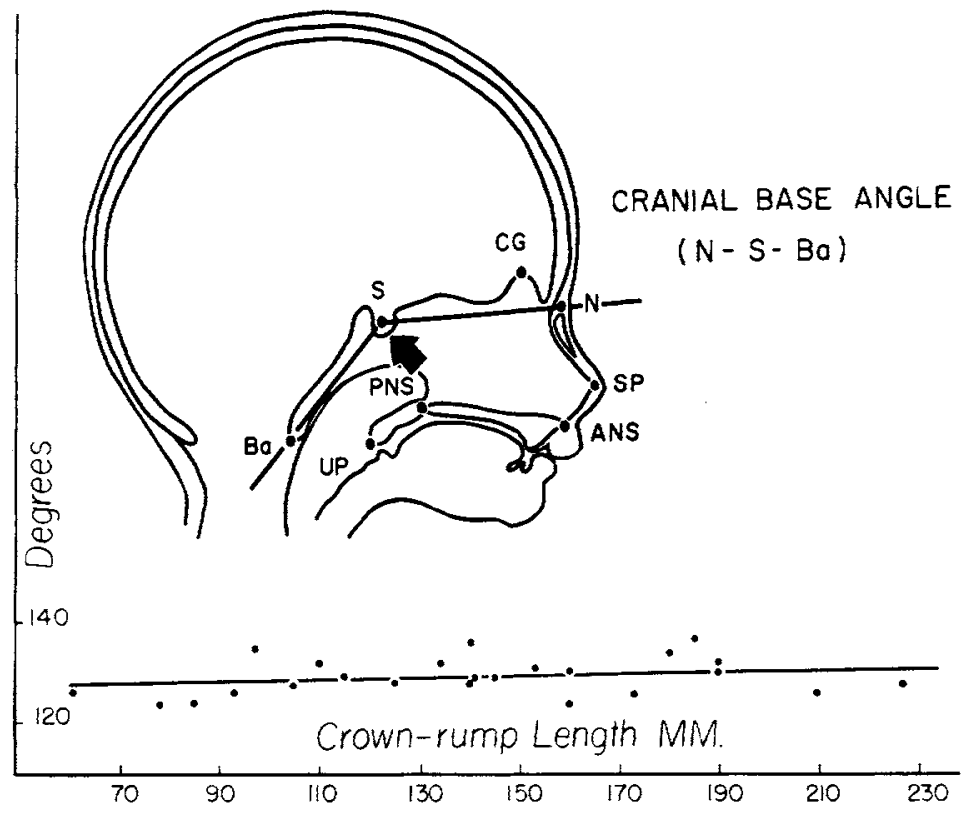

FIg. 3.-Cranial base flexion during the second trimester of development 
TABLE 3

GROWTH IN HEIGHT OF THE FETAL NASAL SEPTUM

A. Regression and correlation analyses

\begin{tabular}{c|c|c|c}
\hline \hline Dimension & $\begin{array}{c}\text { Regression Formula } \\
y=a+(b \times \mathrm{CRL})\end{array}$ & $\begin{array}{c}\text { Correlation } \\
\text { Coefficient }\end{array}$ & $\begin{array}{c}\text { Significance } \\
\text { at 0.01 Level }\end{array}$ \\
\hline Ant. septal height..... & $=9.88+(0.33 \times \mathrm{CRL})$ & .952 & $\begin{array}{c}\text { Yes } \\
\text { Mid. septal height. .... } \\
\text { Post. septal height..... }\end{array}$ \\
\hline
\end{tabular}

B. Results of $t$-test determinations of the significance of the difference between absolute growth rates of the regional heights of the septum

\begin{tabular}{l|c|c|c|c}
\hline Comparison(s) between: & $\begin{array}{c}\text { Arithmetic } \\
\text { Difference } \\
\text { of } b \text {-Values }\end{array}$ & $t$ & $\begin{array}{c}\text { Significance } \\
\text { at } 0.01 \text { Level } \\
(t=2.693)\end{array}$ & $\begin{array}{c}\text { Degrees } \\
\text { of } \\
\text { Freedom }\end{array}$ \\
\hline $\begin{array}{l}\text { Ant. and mid. septal heights. } \\
\text { Ant. and post. septal heights. }\end{array}$ & 0.03 & 0.994 & No & 44 \\
Mid. and post. septal heights. & 0.09 & 3.169 & Yes & 44 \\
\end{tabular}

* Significance at 0.05 level.

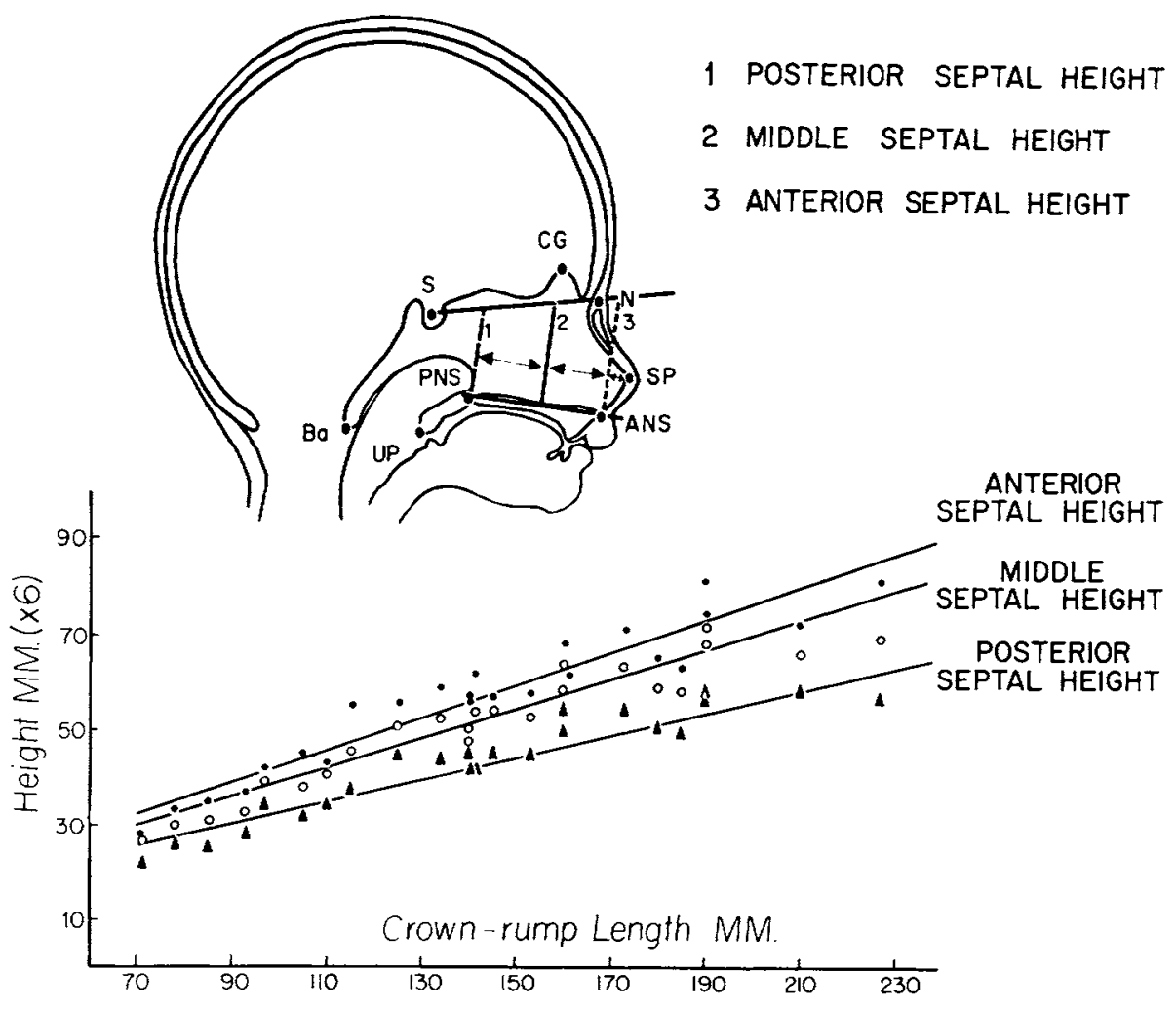

FIG. 4.-Growth in height of the nasal septum 
TABLE 4

Growth in LeNGTh of The Fetal NaSAL SePtum

A. Regression and correlation analyses

\begin{tabular}{|c|c|c|c|}
\hline Dimension & $\begin{array}{c}\text { Regression Formula } \\
y=a+(b \times \text { CRL })\end{array}$ & $\begin{array}{l}\text { Correlation } \\
\text { Coefficient }\end{array}$ & $\begin{array}{l}\text { Significance } \\
\text { at } 0.01 \text { Level }\end{array}$ \\
\hline 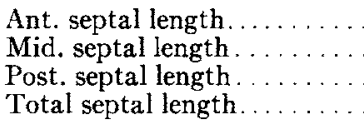 & $\begin{array}{l}=3.94+(0.07 \times \mathrm{CRL}) \\
=4.38+(0.19 \times \mathrm{CRL}) \\
=5.20+(0.31 \times \mathrm{CRL}) \\
=13.52+(0.57 \times \mathrm{CRL})\end{array}$ & $\begin{array}{l}.683 \\
.827 \\
.880 \\
.964\end{array}$ & $\begin{array}{l}\text { Yes } \\
\text { Yes } \\
\text { Yes } \\
\text { Yes }\end{array}$ \\
\hline
\end{tabular}

B. Results of the $t$-test determinations of the significance of the difference between absolute growth rates of the regional lengths of the septum

\begin{tabular}{|c|c|c|c|c|}
\hline Comparison(s) between: & $\begin{array}{l}\text { Arithmetic } \\
\text { Difference } \\
\text { of } b \text {-Values }\end{array}$ & $t$ & $\begin{array}{c}\text { Significance } \\
\text { at } 0.01 \text { Level } \\
(t=2.693)\end{array}$ & $\begin{array}{l}\text { Degrees } \\
\quad \text { of } \\
\text { Freedom }\end{array}$ \\
\hline 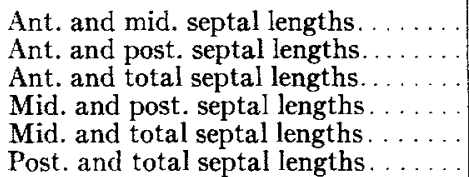 & $\begin{array}{r}0.12 \\
.24 \\
.50 \\
.12 \\
.38 \\
0.26\end{array}$ & $\begin{array}{r}3.782 \\
6.214 \\
13.622 \\
2.672 \\
8.782 \\
5.356\end{array}$ & $\begin{array}{l}\text { Yes } \\
\text { Yes } \\
\text { Yes } \\
\text { No* } \\
\text { Yes } \\
\text { Yes }\end{array}$ & $\begin{array}{l}44 \\
44 \\
44 \\
44 \\
44 \\
44\end{array}$ \\
\hline
\end{tabular}

* Significance at 0.05 level.

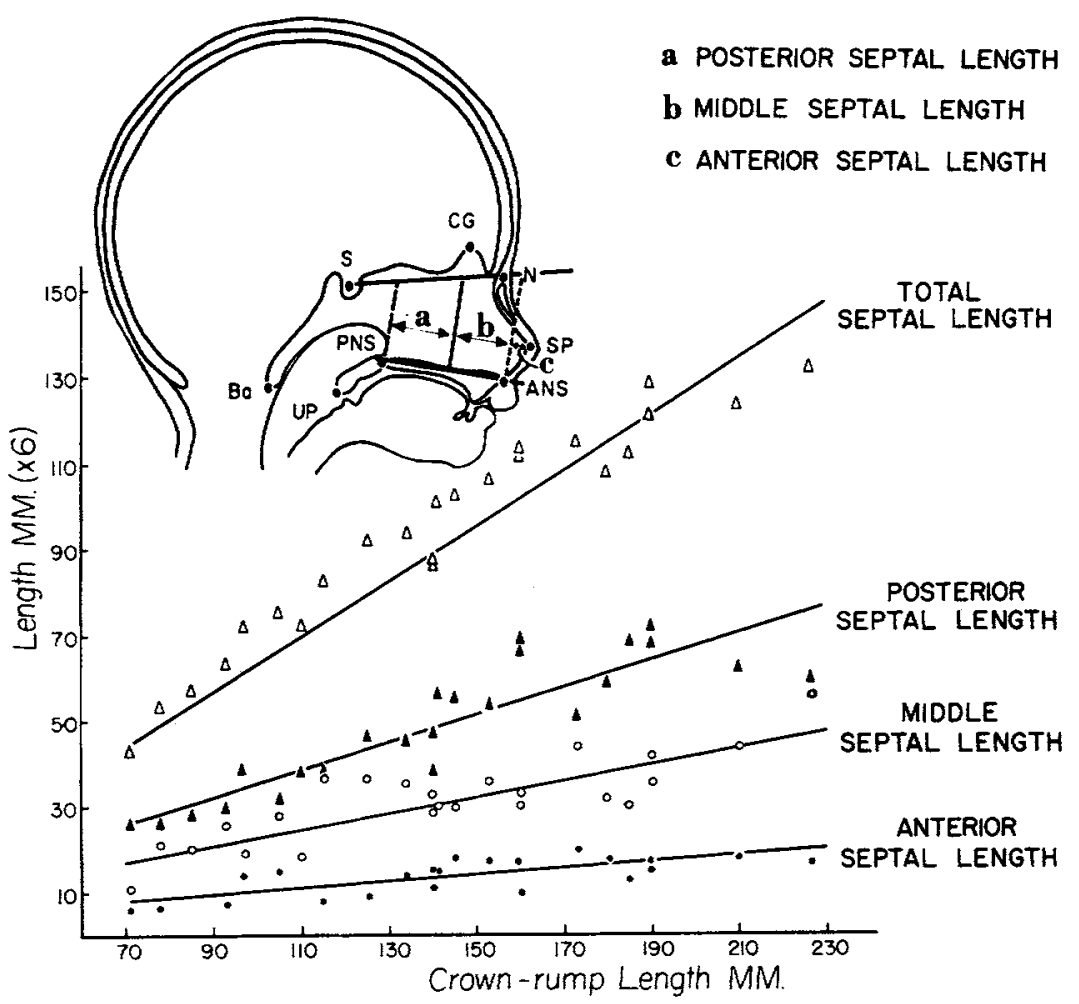

Fig. 5.-Growth in length of the nasal septum 
septal length changes were also significantly correlated with crown-rump length, the largest relative increase in length occurred in the posterior region of the septum and the least relative change in the anterior portion of the septal region. The posterior region increased at 0.31 units per unit increase in crown-rump length. The value of this regression coefficient was significantly greater than that of the middle $(b=0.19)$ and anterior $(b=0.07)$ regions of the septum. In comparison of regional heights of the $70 \mathrm{~mm}$. and the $227 \mathrm{~mm}$. CRL fetuses, the posterior region exhibited an increase of 181 per cent in its height, with the middle and anterior regions undergoing changes of 168 per cent and 124 per cent, respectively.

In order to study the possible changes in the basic shape of the nasal septum, the septal region was circumscribed by (1) the line N-S superiorly, (2) the line ANS-PNS inferiorly, (3) the line N-SP antero-superiorly and posteriorly, and (4) by a perpendicular line constructed from PNS, which extends between the lines N-S and ANSPNS. Any significant changes in the angular relationships of these boundary lines with one another were taken as changes in the basic configuration of the nasal septum.

In the fetuses studied it was found that the angular relationships between the anterior cranial base and the palatal plane, as well as the angle between the anterior cra- nial base and the line N-SP, did not correlate significantly with increases in crownrump length from $70 \mathrm{~mm}$. to $227 \mathrm{~mm}$. (Table 2, Fig. 6). The former relationship had an $r$-value of -0.031 , whereas the latter angular relationship with crown-rump length had a correlation coefficient of $r=0.217$. Although the basic form of the septum based on the above angular relationships appeared relatively stable, the septum did increase in absolute size. This increased size was substantiated by (1) increased lengths of the anterior cranial base and palatal plane and (2) by a significant correlation $(r=0.812$, 0.01 level) between increasing septal area and increasing crown-rump length.

PALATE.-The hard and soft palates increased in length at a rate which was significantly correlated with increasing crownrump length (Table 5, Fig. 7). The length of the hard palate, line ANS-PNS, increased by a regression coefficient of 0.52 units per unit increase in crown-rump length. Based on the data from the regression analyses, a fetus of $227 \mathrm{~mm}$. crown-rump length would demonstrate an increase of 157 per cent from its palatal length in a $70 \mathrm{~mm}$. crown-rump length fetus.

Soft palate length, line PNS-UP, similarly had a significant correlation with increasing fetal size. The regression coefficient for this length exhibited a slope of 0.23 units increase per unit increase in crown-rump

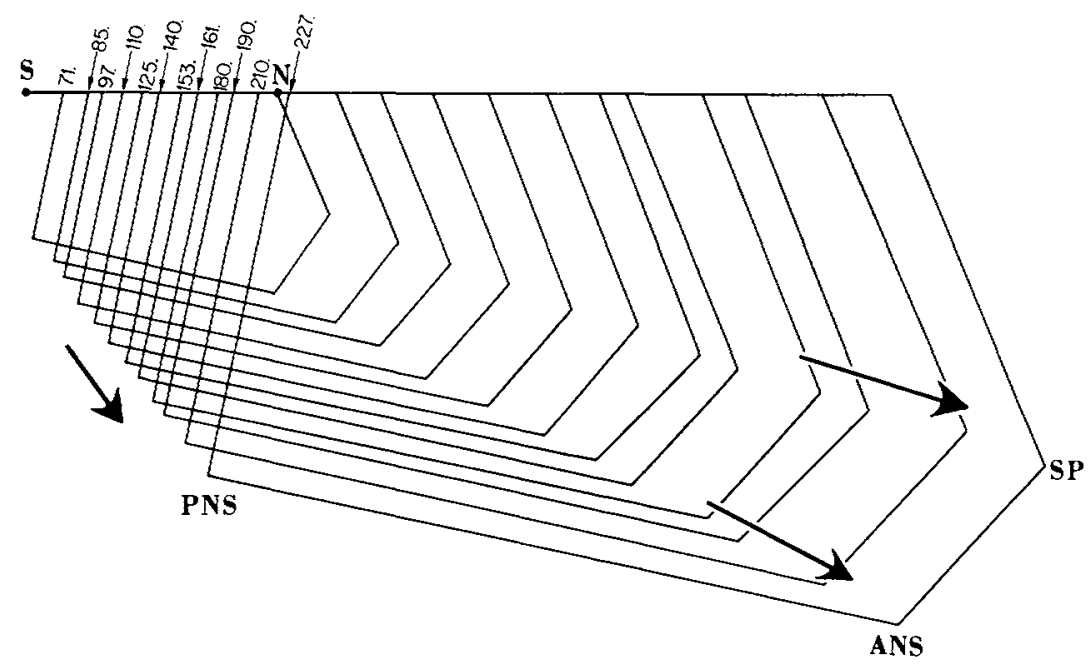

FIG. 6.- Superimposed septal polygons of representative fetuses from 70 through $227 \mathrm{~mm}$. crown-rump length. 
TABLE 5

Growth in Length of the Fetal PaLATe

A. Regression and correlation analyses

\begin{tabular}{|c|c|c|c|}
\hline Dimension & $\begin{array}{l}\text { Regression Formula } \\
y=a+(b \times C R L)\end{array}$ & $\begin{array}{l}\text { Correlation } \\
\text { Coefficient }\end{array}$ & $\begin{array}{l}\text { Significance } \\
\text { at } 0.01 \text { Level }\end{array}$ \\
\hline $\begin{array}{l}\text { Hard palate length.. } \\
\text { Soft palate length... } \\
\text { Total palatal length. }\end{array}$ & $\begin{array}{l}=7.12+(0.52 \times \text { CRL }) \\
=4.59+(0.23 \times \text { CRL }) \\
=7.15+(0.78 \times \text { CRL })\end{array}$ & $\begin{array}{l}.945 \\
.942 \\
.978\end{array}$ & $\begin{array}{l}\text { Yes } \\
\text { Yes } \\
\text { Yes }\end{array}$ \\
\hline
\end{tabular}

B. Results of $t$-test determinations of the significance of the difference between absolute growth rates of the several dimensions of the palate

\begin{tabular}{|c|c|c|c|c|}
\hline Comparison(s) between: & $\begin{array}{l}\text { Arithmetic } \\
\text { Difference } \\
\text { of } b \text {-Values }\end{array}$ & $t$ & $\begin{array}{l}\text { Significance } \\
\text { at } 0.01 \text { Level } \\
(i=2.693)\end{array}$ & $\begin{array}{l}\text { Degrees } \\
\quad \text { of } \\
\text { Freedom }\end{array}$ \\
\hline $\begin{array}{l}\text { Hard and soft palate length........ } \\
\text { Soft and total palate length........ } \\
\text { Hard and total palate length ....... }\end{array}$ & $\begin{array}{r}0.29 \\
.55 \\
0.26\end{array}$ & $\begin{array}{r}2.467 \\
10.818 \\
2.892\end{array}$ & $\begin{array}{l}\text { No* } \\
\text { Yes } \\
\text { Yes }\end{array}$ & $\begin{array}{l}43 \\
42 \\
43\end{array}$ \\
\hline
\end{tabular}

* Significance at 0.05 level.

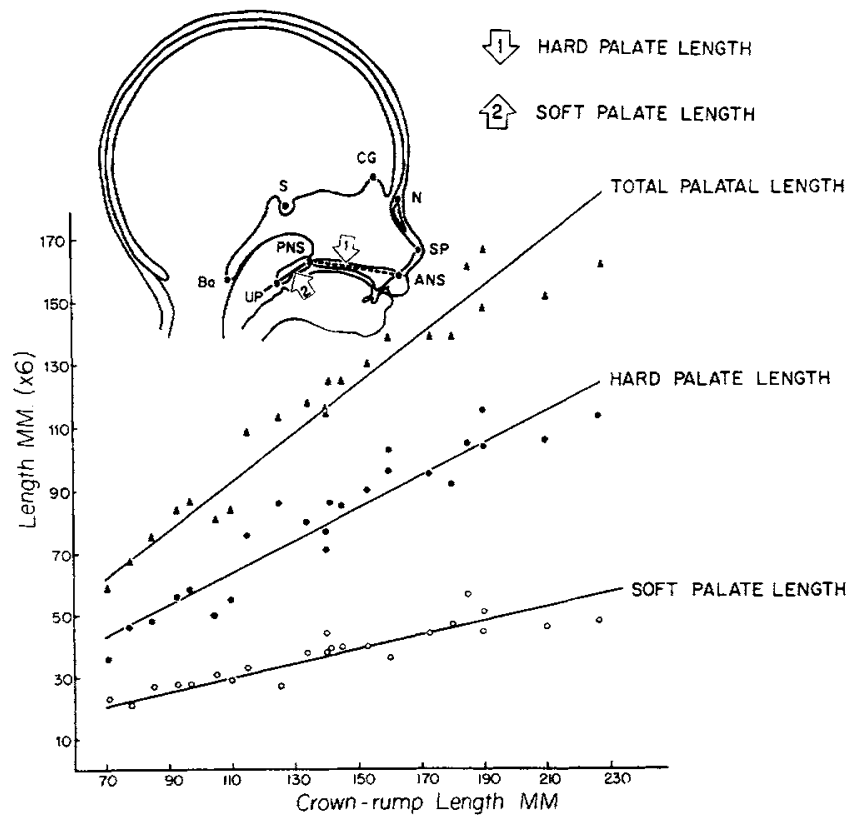

FIG. 7.-Growth in length of the hard and soft palates 
length. A $t$-test comparison of the regression coefficients for the hard and soft palates showed a significant difference in value at the 0.05 level. Accordingly, the soft palate in the $70 \mathrm{~mm}$. crown-rump length fetus comprised only 33 per cent of the total length of the palate as measured from ANS to UP. This proportionality continued throughout the second trimester of development in that the largest specimen ( $227 \mathrm{~mm}$. CRL) had a soft palate length which represented 31 per cent of the total palatal length.

This study also suggests that no significant correlation exists between increasing crown-rump length and changes in the angular relationships between the palatal plane and selected basicranial planes (Table 2, Fig. 8). This apparent angular stability was based on the observed interrelations of the line ANS-PNS with the lines S-N, S$\mathrm{Ba}$, and $\mathrm{Ba}-\mathrm{N}$.

The clivopalatal angle formed by the intersection of the palatal plane with the line $\mathrm{S}-\mathrm{Ba}$ did not show a significant change with changes in crown-rump length $(r=$
-0.282). The palatal plane relationship with the basicranial axis (line $\mathrm{N}-\mathrm{Ba}$ ) similarly exhibited a lack of significant correlation with crown-rump length. Although the value of this correlation coefficient $(r=$ -0.466) did indicate a slight decrease in angular value with increasing crown-rump length, the change was negligible. The same relative angular stability was found to exist for the relationship between the anterior cranial base (line $\mathrm{N}-\mathrm{S}$ ) and the palatal plane. This angle demonstrated the least correlation with crown-rump length $(r=$ $-0.031)$.

\section{Discussion}

Group trends in this quantitative facialgrowth study suggest a relative constancy in facial shape during the second trimester of fetal development. Based on cross-sectional mean data, the geometric form of the upper face can be recognized as a stable entity from the beginning of the fourth month through the end of the sixth month. This is a pattern which has not been re-

ANGLES BETWEEN PALATAL PLANE AND:

I ANTERIOR CRANIAL BASE

2 POSTERIOR CRANIAL BASE

3 BASICRANIAL AXIS

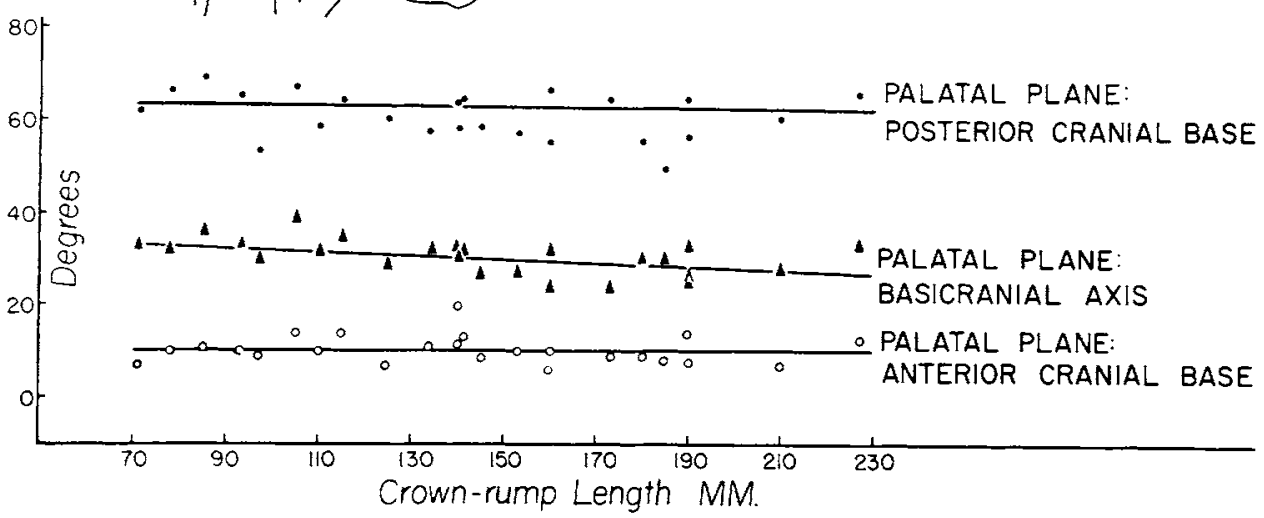

FIG. 8.- Angular relationships between the palatal plane and selected basicranial planes 
ported previously, although it was suspected by several investigators.

Although the second trimester is developmentally as well as chronologically distant from childhood, the pattern of facial growth in this fetal sample infers a direct continuity with studies postulating the stability of facial form in the early years of childhood. In 1937 Broadbent ${ }^{13}$ concluded, on the basis of a mean composite pattern of facial growth, that the shape of the face was established at the time of full eruption of the deciduous teeth. Brodie, ${ }^{14}$ however, placed the establishment of facial form at the beginning of the third postnatal month. Later, Ortiz and Brodie ${ }^{15}$ found that the geometric form of the face could be recognized as a stable pattern even earlier than the third month, e.g., at birth. Their study emphasized the need to explore patterns of prenatal facial growth as a means for a better understanding of facial growth after birth.

Although the similarity of the results from cephalometric analyses, the quantitative observations in the present fetal study, and the above-mentioned postnatal investigations support the concept of a developmental continuity in the patterns of preand postnatal facial growth, this conception must be regarded as tentative until analyses of third trimester fetuses are completed. In spite of the present void in third-trimester facial-growth data, a review of general prenatal growth curves makes this suggestion of direct continuity between pre- and postnatal facial-growth patterns a reasonable effort. During prenatal development body growth is characterized by a sigmoid curve which indicates a slow rate of absolute linear growth in the embryonic period followed by a period of rapid incremental growth in the second trimester and thereafter a slow decline or plateauing (Toldt, ${ }^{16}$ Mall, ${ }^{17}$ Zangemeister, ${ }^{18}$ Streeter ${ }^{19}$ ). The author's preliminary observations of third trimester fetuses lend support to this sigmoid growth curve in prenatal development in which the fetus undergoes its greatest growth changes in the second trimester. On the basis of this evidence, one may infer that the similarity of second trimester facialgrowth patterns and those of the neonatal period is likely and merits furthor discussion.

In addition to the apparent stability of the geometric form of the fetal upper face, cross-sectional mean data also indicate other distinct patterns of craniofacial grow th relative to the cranial base, nasal septum, and palate. First, sagittal growth of each of these contiguous areas of the upper face demonstrates a significant relationship with increasing crown-rump length of the fetus. Thus incremental growth in length occurs concomitantly with increases in body stature. Second, the directional growth of the upper face, as indicated by the spatial behavior of the palatal plane, shows a forward and downward vector relative to the anterior cranial base and the landmark sella.

The distinct growth patterns of each of the component areas of the upper face are as interesting as the general growth trends discussed above. Observations on the relative growth rates of the presellar and postsellar segments of the cranial base agree with previous workers who found that the anterior part of the cranial base grew at a greater rate than did the posterior cranial base in their antero-posterior dimension. The anterior cranial base characteristically represents approximately 61 per cent of the total length of the base. As one registers on the reference landmark sella, it becomes apparent that the anterior cranial base is growing forward and upward, whereas the posterior base is growing backward and downward. As these two base segments are increasing in absolute length, the angular relationship of the anterior and posterior cranial base segments, as one might suspect from the earlier discussion on general angular stability, does not show significant changes in value with increases in crownrump length.

The distinctly human feature of cranial base flexure is perhaps the most frequently studied characteristic of the basal region of the skull. The angulation of the cranial base has received numerous phylogenetic and ontogenetic explanations. Since a thorough discussion of the phylogenetic behavior of the cranial base angle is beyond the scope of the present paper, the reader is referred to several stimulating and unsettled accounts of basal flexure which appear in the literature. ${ }^{20-24}$ Ontogenetically, cross-sectional data reveal no significant changes in the nasion-sella-basion angle from the first year of life through late adolescence. ${ }^{25-29}$ These 
studies indicate mean angular values of approximately 130 to 132 degrees. Interestingly, the same angle in the fetuses studied also shows a similar angle of approximately 129.5 degrees as a mean value for the second trimester; preliminary observation in third trimester fetuses shows no marked changes from the second trimester value. Ford ${ }^{10}$ has also shown this angle to have a value of 150 degrees at term. However, he did show an increase of 19 degrees in this angle from 10 weeks to term-a finding which could not be confirmed by this author.

It is interesting to speculate on the relation between the component tissues of the cranial base and the growth curves depicting antero-posterior growth. The growth curve is seemingly unchanged by the sequential development of the cranial base from an early basal layer of dense embryonic mesenchyme beneath the developing brain to a preponderance of cartilage extending as a bar from the occipital area anteriorly to the ethmonasal region, and, finally, to a chondro-osseous complex. It is during this latter stage that there is a progressive encroachment of bone into the previously singular mass of cartilage. ${ }^{30}$ It appears that the character of the growth curve seen at the beginning of the fetal period when cartilage prevailed in the cranial base continues seemingly unaffected as the tissue composition of the cranial base is in developmental flux from cartilage to bone. One may further speculate that the growth curve is dependent on growth of cartilage regardless of whether it is in the form of an elongated bar or in the form of synchondroses later in the fetal period.

The distinct difference in the linear and angular growth pattern described for the cranial base also characterized the growth changes of the palate or nasal floor. Spatial behavior of the anterior and posterior nasal spines was a primary indicator of palatal growth. A composite profile of the fetal upper face clearly showed that these two landmarks migrated forward and downward as the distance between the nasal spines increased. As a corollary to this sagittal growth pattern, the hard palate or nasal floor descended anteriorly in a parallel manner so that a constant angular relationship with the anterior cranial base was maintained. This constant angular relationship between the anterior cranial base and nasal floor during the second trimester in utero was strikingly similar to findings of crosssectional and longitudinal studies of the same relationship from birth through adolescence. ${ }^{13-15,31,32}$

The hard and soft palates did not contribute equally to the total length of the palate. The soft palate comprised approximately one-third of the total palatal length, and this proportionality did not change during the second trimester. This distinct growth differential may be significant in normal palatopharyngeal closure or competence. Since the soft palate is attached to the posterior nasal spine, it is carried forward with the movement of the hard palate. However, Calnan ${ }^{33}$ has shown that palatopharyngeal competency depends, in part, on the length and ability of the soft palate to contact the pharyngeal mucosa. Furthermore, the soft palate must also maintain its muscular attachments and functional relationships with the lateral walls of the oropharynx. This being the case, it is suggested that there is a compensatory posterior growth of the soft palate to aid in palatopharyngeal competence. This suggested compensatory growth of the soft palate possibly continues up to the end of the first. year, after which growth of the posterior nasal spine is no longer forward and downward but primarily in one vector-downward. ${ }^{13,14}$

Our final consideration of the fetal upper face involves the sagittal growth of the nasal septum. On the basis that a constant angular relationship was found between the anterior cranial base and the nasal floor, it was not unexpected to find that the posterior region of the septum grew greatest in length and least in height. In other words, a postero-anterior gradient characterized the mean growth rates involving septal length. Conversely, changes in septal height excluding the vestibular septum were greater anteriorly than in the posterior region, i.e., an antero-posterior gradient.

Although the present study clearly shows a parallelism between the forward and downward growth of the cartilaginous nasal septum and hard palate, recognition of the nasal septum as the causal agent in the forward and downward growth of the upper face is beyond the scope of this study. It is 
interesting, however, to relate the growth pattern of the septum to reported hypotheses of prenatal facial growth. In a phylogenetic treatment of the human face, Gregory $^{34}$ has suggested that since the nasal septum is "firmly anchored" to the mid-line region of the maxilla, as the maxilla moves downward and forward, it carries with it the nasal septum. In this situation one could consider the growth of the septum as a compensatory mechanism which maintains the spatial continuity between the cranial base and hard palate. Schultz, ${ }^{35}$ on the other hand, subjectively has described the fetal nasal septum as growing downward and forward, increasing the depth of the nasal fossae. Scott $t^{35-37}$ re-emphasized the possible role of the nasal septum as a primary effector of fetal development. Until the third year of life spatial changes in the upper face are regulated predominately by the downward and forward growth or "thrust" of the nasal septum. This possible role of the nasal septum is most interesting and might very well be correct. However, further study of the septum, cephalometrically and histologically, is needed.

Finally, the present fetal-growth study describes the growth behavior of the nasal profile which until now has not been quantitatively analyzed, although subjectively described by several investigators. Schult $z^{38,39}$ and Patten ${ }^{30}$ have observed that the profile of the external nose becomes evident as an indentation between the antero-superior slope of the external nose and prominent forehead as early as the third month in utero and appears to remain relatively unchanged throughout fetal life. Cross-sectional data of this study indicate that the frontonasal angle (S-N-SP), designed to reflect the profile of the nasal region, does indeed show no significant change with increasing crown-rump length as seen in fetuses from 70 through $227 \mathrm{~mm}$. Although the procumbent external nose and related region of the nasal septum is growing in absolute size, its form and size change the least relative to major incremental changes in the endofacial septum which divides the nasal cavities proper.

\section{Summary}

Changes in size, shape, and proportion of the nasomaxillary region have been studied in human fetuses representing the fourth through the sixth month of development. For this a series of linear and angular measurements of the cranial base, nasal septum, and palatal regions have been made. The data were related to crown-rump length and subjected to group statistical analyses to demonstrate growth trends of the upper face.

The findings suggested that several distinct patterns of nasomaxillary growth may exist during the period studied. First, angular relationships between contiguous areas of the nasomaxillary region showed no significant changes with increasing crown-rump length. Second, linear measurements of the cranial base, nasal septum, and palate were correlated with increases in crown-rump length. Third, the directional growth pattern of the upper face exhibited a downward and forward growth away from the anterior cranial base and the landmark sella.

The author is deeply indebted to Dr. Alexander Barry for his stimulating advice during the initial stages of this study and to the Director of the University of Michigan Computing Center for assistance in the statistical analyses of the data reported here.

\section{References}

1. Macklin, C. C. The Skull of a Human Fetus of 40 mm., Amer. J. Anat., 16:317-426, 1914.

2. Kernan, J. D. The Chondrocranium of a $20 \mathrm{~mm}$. Human Embryo, J. Morph., 27:605-45, 1916.

3. LEwIs, W. H. The Cartilaginous Skull of a Human Embryo Twenty-one Millimeters in Length, Contr. Embryol. Carneg. Instn., 9:299-324, 1920.

4. Chase, S. W. The Early Development of the Human Premaxilla, J. Amer. dent. Ass., 29:1991-2001, 1942.

5. Woo, J. K. Ossification and Growth of the Human Maxilla, Premaxilla, and Palate Bone, Anat. Rec., 105:737-62, 1949 .

6. Kraus, B. S. Prenatal Growth and Morphology of the Human Bony Palate, $J$. dent. Res., 39:1177-99, 1960.

7. Scammon, R. E., and Calkins, L. A. The Development and Growth of the External Dimensions of the Human Body in the Fetal Period, p. 367. Minneapolis: University of Minnesota Press, 1929.

8. Inman, V. T. Observations on the Growth and Development of the Human Fetal Cranium, p. 81. Unpublished $\mathrm{Ph} . \mathrm{D}$. dissertation, University of California, 1934.

9. Moss, M. L., Noback, C. R., and Robertson, C. G. Growth of Certain Human Fetal Cranial Bones, Amer. J. Anat., 98:191-204, 1956.

10. Ford, E. H. R. The Growth of the Foetal Skull, $J$. Anat. (Lond.), 90:63-72, 1956.

11. KUMMER, B. Untersuchungen über die ontogenetische Entwicklung des menschlichen Schadelbasiswinkels, $Z$. Morph. Anthrop., 43:331-60, 1952

12. Krogman, W. M., and Sassouni, V. A Syllabus in Roentgenographic Cephalometry, pp. 1-366. Philadelphia: Philadelphia Center for Research in Child Growth, 1957.

13. Broadbent, B. H. The Face of the Normal Child, Angle Orikodont., 7:183-207, 1937. 
14. Brodie, A. G. On the Growth Pattern of the Human Head from the Third Month to the Eighth Year of Life, Amer. $J$. Anat., 68:209-62, 1941.

15. ORTIZ, M. H., and BRodie, A. G. On the Growth of the Human Head from Birth to the Third Month of Life, Anat. Rec., 103:311-33, 1949.

16. Toud, C. Über die Altersbestimmung menschlicher Embryonen, Prag. med. Wschr. 4:121-40, 1879.

17. Mali, F. P. Determination of the Age of Human Embryos and Fetuses. In Humen Embryology, ed. F. KeIBEL and F. P. MALL, Vol. 1: chap. 8, pp. 180201. Philadelphia: J. P. Lippincott Co., 1910.

18. Zangemeister, W. Die Altersbestimmung des Foetus nach graphischer Methode, Z. Geburtsh. Gynäk., 69: $127-42,1911$.

19. Streeter, G. L. Weight, Sitting Height, Head Size, Foot Length, and Menstrual Age of the Human Embryo, Contr. Embryol. Carneg. Instn., 11 :143-70, 1920.

20. BoLK, L. Über Lagerung, Verschiebung und Neigung des Foramen Magnum am Schadel des Primaten, Z. Morph. Anthrop., 17:611-92, 1915.

21. Cameron, J. The Main Angle of Cranial Flexion (the Nasion-Pituitary-Basion Angle), Amer. $J$, phys. Anthrop., 10:275-79, 1927.

22. WeIDENREICH, F. The Brain and Its Role in the Phylogenetic Transformation of the Human Skull, Trans. Amer. Phil. Soc., N.S., 31:321-442, 1941.

23. Dabelow, A. Über Korrelationen in der phylogenetischen Entwicklung der Schadelform. Morph. $J b$., 67:84-133, 1931.

24. DuBrul, E. I., and Laskin, D. M. Preadaptive Potentialities of the Mammalian Skull: An Experiment in Growth and Form, Amer. J. Anat., 109:11732,1961 .

25. BJoRk, A. Cranial Base Development, Amer. $I$. Orthodont., $41: 198-226,1955$.
26. Brodie, A. G., JR. The Behavior of the Cranial Base and Its Components as Revealed by Serial Cephalometric Roentgenograms, Angle Orthodont, 25:148-60, 1955.

27. Stramrud, L. External and Internal Cranial Base: A Cross-sectional Study of Growth and of Association in Form, Acta odont. scand., 17:239-66, 1959.

28. KoskI, K. Some Aspects of the Growth of the Cranial Base and the Upper Face, Odont. T., 68:344-58, 1960.

29. MCNeill, R. W. A Roentgenographic Cephalometric Study of Nasopharyngeal and Cranial Base Growth in Cleft Palate Children, pp. 1-38. Unpublished M.S. thesis, University of Pennsylvania.

30. Patten, B. M. Human Embryology, pp. 248-91. New York: McGraw-Hill Book Co., Inc. 1953.

31. Rosenberger, H. D. Growth and Development of the Naso-respiratory Area in Childhood, Ann. Otol. (St. Louis), 43:495-513, 1934.

32. KoskI, K. Growth Changes in the Relationships between Some Basicranial Planes and the Palatal Plane, Suom. Hammasläak. Toim., 57:15-26, 1961.

33. CalnaN, J. Palato-pharyngeal Incompetence in Speech. In Congenital A nomalies of the Face and Associated Structures, pp. 104-22, ed. S. Pruzansky, Springfield, Illinois: C. C Thomas Co., 1961.

34. GREGORY, W. K. Our Facefrom Fish to Man, pp. 15372. New York: G. P. Putnam's Sons, 1929.

35. Scotr, J. H. The Cartilage of the Nasal Septum, Brit. dent. J., 95:37-43, 1953.

36. 7 . The Growth of the Human Face, Proc. roy. Soc. Med., 47:91-100, 1954.

37. - The Cranial Base, Amer. J. phys, Anthrop., $16: 319-48,1958$

38. Schultz, A. H. Relation of the External Nose to the Bony Nose and Nasal Cartilages in Whites and Negroes, Amer. J. phys. Anthrop., 1:329-38, 1918.

39. groes, Amer. . Fetal Growth in Man, ibid., 6:389-99, 1923. 